\title{
The relation of the true conjugate to maternal height and obstetric performance in Ghanaians
}

\author{
S.W.K. Adadevoh ${ }^{\mathrm{a}}$, C. Hobbs ${ }^{\mathrm{b}}$ and T.E. Elkins $\mathrm{s}^{\mathrm{c}}$ \\ -Department of Obstetrics and Gynecology, University of Science and Technology, School of Medical Sciences, Kumasi (Ghana) \\ 'Department of Epidemiology and Biostatistics, McGill University, Montreal (Canada) and 'Department of Obstetrics and \\ Gynecology, University of Michigan Medical Center, Ann Arbor, Michigan (U.S.A.) \\ (Received January 22nd, 1988) \\ (Revised and accepted April 5th, 1988)
}

\begin{abstract}
The true conjugate was determined intraoperatively with a caliper in 114 Ghanaian women and was correlated with their height, obstetric performance and fetal dimensions. Those patients undergoing cesarean section for cephalopelvic disproportion (Group Ia) were found to have a significantly shorter mean true conjugate $(9.54 \mathrm{~cm} \pm 0.63$ S.D.) and mean body height $(152.68 \mathrm{~cm} \pm 5.46$ S.D.) and a smaller true conjugate - fetal biparietal diameter difference $(10.93 \mathrm{~mm})$ than those who had no cephalopelvic disproportion (Group Ib) and whose mean measurements were $10.61 \mathrm{~cm} \pm 0.81$ S.D., $157.20 \mathrm{~cm} \pm 5.69$ S.D. and $21.50 \mathrm{~mm}$, respectively $(P=0.0001)$. Recommendations for appropriate referral of rural clinic patients and for selection of patients for repeat cesarean sections are based on the above findings.
\end{abstract}

Keywords: True conjugate; Maternal height; Previous obstetric performance; Fetal dimensions; Cephalopelvic disproportion; Previous cesarean section.

\section{Introduction}

Cephalopelvic disproportion (CPD),

$0020-7292 / 89 / \$ 03.50$

(C) 1989 International Federation of Gynecology and Obstetrics Published and Printed in Ireland defined as the failure of the fetus to pass safely through the pelvis on account of mechanical hindrances, is common among Africans and is a major cause of maternal and perinatal mortality and morbidity. The commonest cause of this condition is a contracted pelvis in the presence of a normal or averagesized baby. The reasons for pelvic contraction may be genetic or nutritional (e.g. rickets, osteomalacia) or the result of bony diseases such as tuberculosis, osteomyelitis and poliomyelitis. Contracted pelvis is known to be more common among women less than 152 $\mathrm{cm}(5 \mathrm{ft})$ in height than among those over 152 $\mathrm{cm}[2]$.

The value of the true conjugate (TC) has not been determined among Ghanaian women. Modern facilities for pelvic measurement such as radiology and ultrasound and also technical expertise are not available in the vast majority of hospitals. Hence prior screening by means of modern techniques of primigravid patients suspected of pelvic contraction is not often possible in Ghana. Clinical pelvic assessment by the less accurate digital examination and a careful conduct of trial of labor in cases suspected of CPD is the usual practice among clinicians in Ghana as in most of Africa. This practice, however, has its limitations in patients who have had a previous cesarean section (c-section) for an 
unknown indication as is often the case of such patients referred from other hospitals).

The purpose of this study is:

(1) to measure the true conjugate using a caliper in the absence of modern facilities for pelvimetry at the Komfo Anokye Teaching Hospital (KATH) in Kumasi, Ghana;

(2) to relate the true conjugate to the maternal height and previous obstetric performance;

(3) to measure and then determine the relation of the fetal birthweight (BW), the biparietal diameter (BPD), and the suboccipitobregmatic diameter (SOB) to the maternal height and outcome of delivery;

(4) to deduce from the study some basic data and observations on the average birthweight and fetal head dimensions of Ghanaian babies delivered by cesarean section.

\section{Subjects and methods}

In the 6-month period from May to October 1986, the true conjugate was measured intraoperatively in 114 randomly selected Ghanian women. Group I included 79 patients aged 16-40 who were pregnant and had cesarean section for various indications. Group II included 35 patients aged 16-70 who were not pregnant and had laparotomy for various reasons. The patients in Group I were further subdivided into those who had csection for CPD (Group Ia) and those who had c-section for other reasons (Group Ib). At admission a form was completed for each patient with the following details: name, address, hospital file number, last menstrual period (LMP), estimated duration of pregnancy (in weeks), age, parity, height, mode of previous deliveries, outcome of previous deliveries, indications for both present and any previous cesarean section(s), and details of the baby, namely: sex, birthweight, biparietal diameter, suboccipito-bregmatic diameter and gestational age.

During the operation a pelvic caliper, the DeLee's pelvimeter graduated in centimeters was used to measure the true conjugate by placing one arm of the caliper at the midpoint of the sacral promontory and the other arm approximately $0.5 \mathrm{~cm}$ down the midline of the upper posterior border of the pubic symphysis in order to estimate the shortest antero-posterior pelvic inlet diameter which is the shortest distance between the promontory and the pubic symphysis, the obstetrical true conjugate. In cases of cesarean section the measurement was taken after delivery of the baby and after suture of the uterine incision and the utero-vesical peritoneum followed by eversion and lateral displacement of the contracted uterus. The heights of all patients were taken using the same scale (graduated in $\mathrm{cm}$ ). In cases of emergency sugery this was done just before discharge of the patient usually between the 8th and the 10th postoperative day when the patient was able to stand properly erect without any abdominal

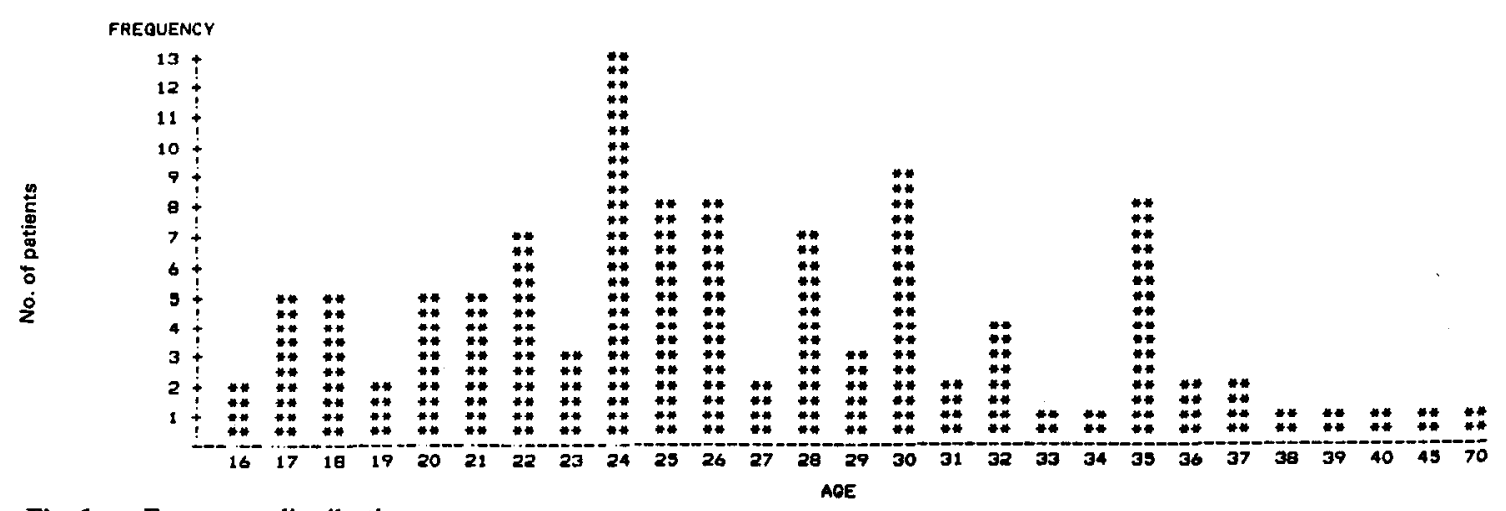

Fig. 1. Frequency distribution: age. 


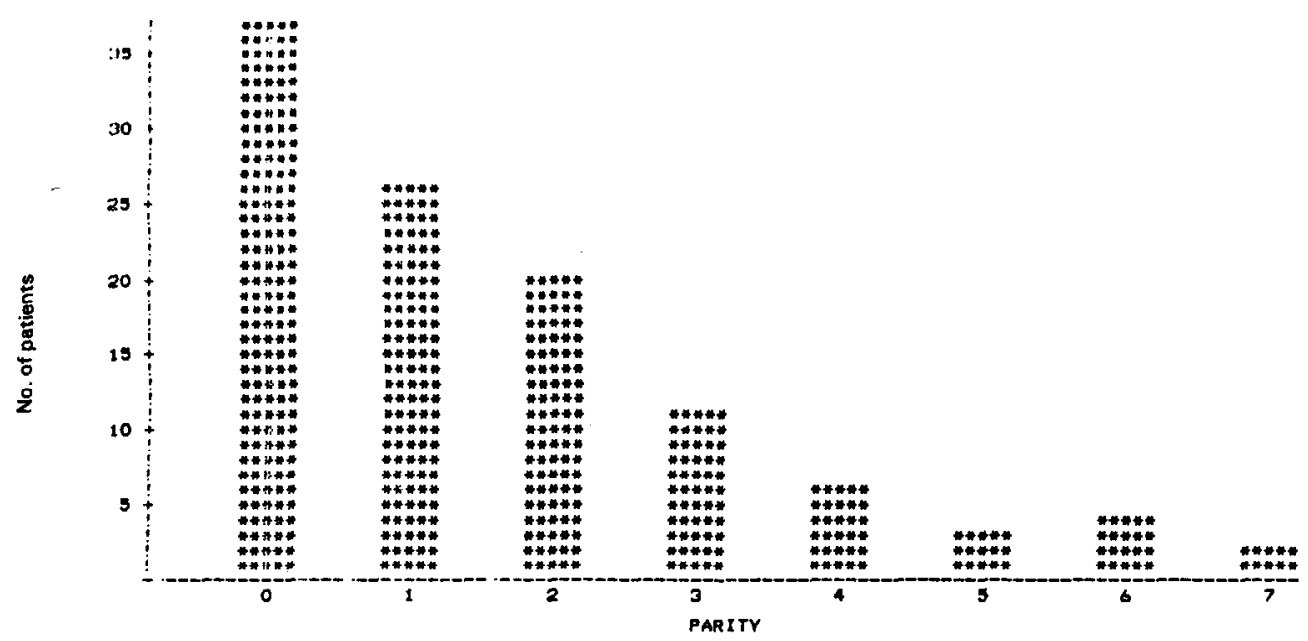

Fig. 2. Frequency distribution: parity.

wound pain. In elective cases, the heights were measured at the time of admission. The birthweights of the babies were determined within $1 \mathrm{~h}$ of birth using the same scale (graduated in g) and at the same time also the fetal biparietal and suboccipito-bregmatic diameters were measured with the same fetal head caliper, graduated in centimeters. No attempt was made to correlate any of these measurements with the general classification of pelvic configurations (i.e. anthropoid, gynecoid, platypoid), since these are relatively subjective categories.

\section{Results}

\section{Frequency distribution}

The frequency distributions for age, parity, height and true conjugate of all patients are shown in the histograms in Figs. 1, 2, 3 and 4, respectively.

\section{Mean values}

Table I shows the mean age, parity, height and true conjugate values for (1) all 114 subjects in the study, (2) Group I and II. For all

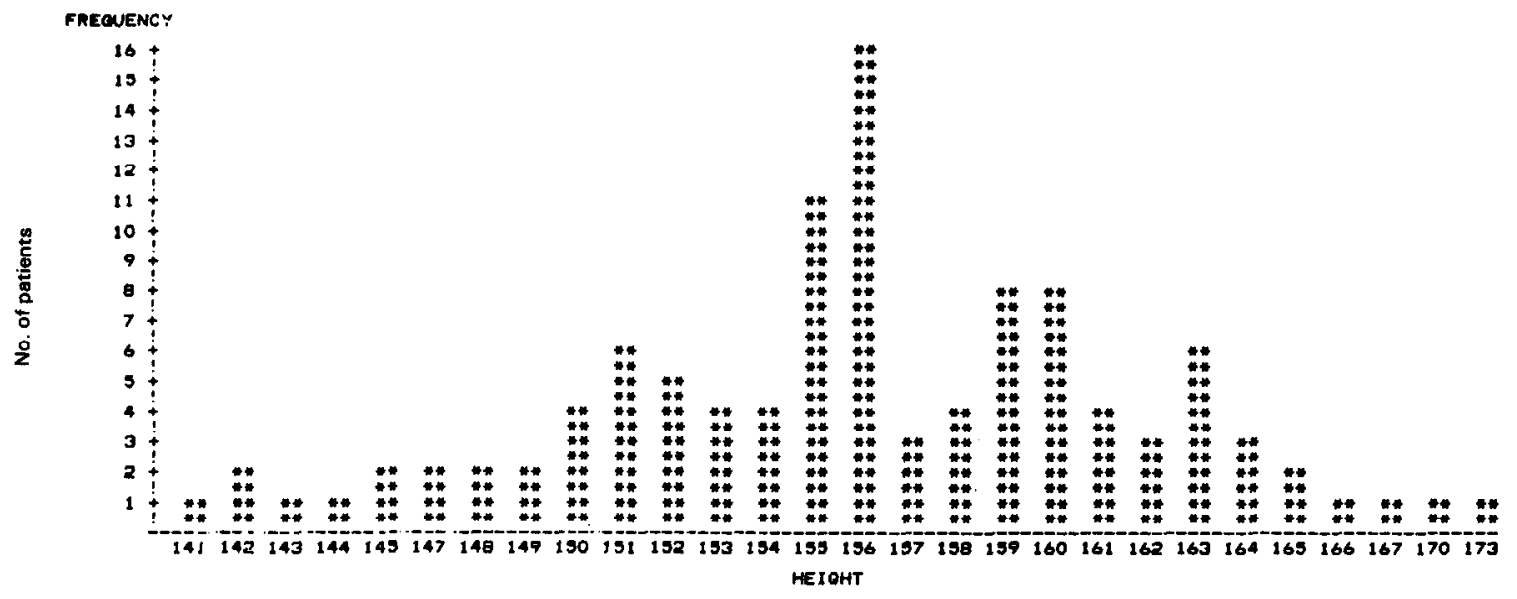

Fig. 3. Frequency distribution: height. 


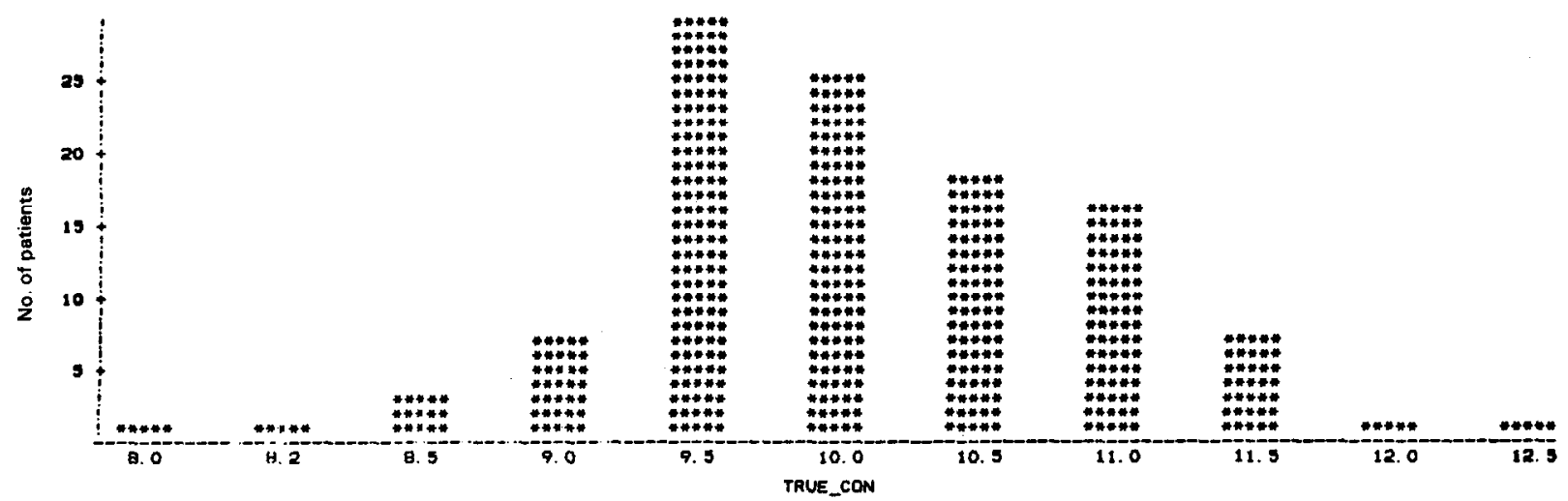

Fig. 4. Frequency distribution: true conjugate.

subjects $(N=114)$, the mean age was 26.78 \pm 7.41 S.D., mean parity $1.67 \pm 1.86$ S.D., mean height $156.06 \pm 5.93$ S.D. and mean true conjugate $10.14 \pm 0.84$. For all patients who had cesarean sections $(N=79)$ the means were: age $25 \pm 6.00$ S.D., parity 1.63 \pm 2.02 S.D., height $155.23 \pm 6.00$ S.D. and true conjugate $10.15 \pm 0.91$ S.D. For all patients who had laparotomy the mean values were age $29.54 \pm 9.41$ S.D., parity $1.74 \pm$ 1.46 S.D.; height $157.91 \pm 5.42$ S.D. and true conjugate $10.11 \pm 0.69$.

Table II shows the mean values of height and true conjugate in height groups. Figure 5 shows the plot of height against the true conjugate. A Pearson product moment correlation of height and true conjugate for 113 patients in the study (excluding the individual whose height was missing) was found to be equal to $0.51(r=0.51)$. This was statistically significant at the 0.0001 level of significance $(P=0.0001)$.

\section{Mode and outcome of previous deliveries}

Table III shows the distribution of the mode and outcome of previous deliveries for all patients. The highest rates of cesarean section deliveries occurred in patients who had 1 , 2 or 6 prior deliveries.

\section{Indications for cesarean section}

The patients were grouped according to the indications for the c-section viz: CPD, fetal distress, antepartum hemorrhage (APH) and "others". "Others" included patients having repeat cesarean section and whose indica-

Table I. Mean Age, parity, height and true conjugate for (1) all subjects, (2) Groups I and II. N = number of patients; SD = standard deviation.

\begin{tabular}{lrrr}
\hline & $\begin{array}{c}\text { All subjects }(N=114) \\
\text { mean } \pm \text { S.D. }\end{array}$ & $\begin{array}{l}\text { Group I }(N=79) \\
\text { mean } \pm \text { S.D. }\end{array}$ & $\begin{array}{l}\text { Group II }(N=35 \\
\text { mean } \pm \text { S.D. }\end{array}$ \\
\hline Age (years) & $26.78 \pm 7.41$ & $25.56 \pm 6.00$ & $29.54 \pm 9.41$ \\
Parity & $1.67 \pm 1.86$ & $1.63 \pm 2.02$ & $1.74 \pm 1.46$ \\
Height $(\mathrm{cm})(N=113)^{2}$ & $156.06 \pm 5.93$ & $155.23 \pm 6.00$ & $157.91 \pm 5.42$ \\
True conjugate $(\mathrm{cm})$ & $10.14 \pm 0.84$ & $10.15 \pm 0.91$ & $10.11 \pm 0.69$ \\
\hline
\end{tabular}

One patient's height was missing. 
Table II. Mean height and true conjugate in height groups.

\begin{tabular}{lrr}
\hline & Height $(\mathrm{cm})$ & \multicolumn{1}{l}{$\begin{array}{l}\text { True conjugate } \\
(\mathrm{cm})\end{array}$} \\
\hline$<155 \mathrm{~cm}(N=37)$ & $149.62 \pm 3.71$ & $9.63 \pm 0.67$ \\
$155-160 \mathrm{~cm}(N=53)$ & $157.07 \pm 1.83$ & $10.20 \pm 0.74$ \\
$>160 \mathrm{~cm}(N=23)$ & $164.09 \pm 3.03$ & $10.80 \pm 0.85$ \\
\hline
\end{tabular}

tion(s) for the previous c-section(s) were not definitely known to be CPD. Table IV shows the distibution according to indication for the current and previous c-section(s). CPD was the indication for c-sections in $34(43 \%)$ of the cases and this proportion increased with increasing numbers of c-sections namely $70 \%$ and $75 \%$ of all those who had two and three c-sections, respectively. Fetal distress, APH, and others made up together $57 \%$. Thus CPD alone constituted $43 \%$ of the cases.

Birthweight (BW), biparietal diameter (BPD) and suboccipito-bregmatic diameters (SOB) of babies delivered by cesarean section

The BW, the BPD, and the SOB diameters of 74 babies delivered by c-section were measured. Forty babies were males and 34 females. Twins and babies of less than 38 weeks gestational age were excluded from the computation of the results $(N=5)$. Table $V$ shows the mean values of $\mathrm{BW}, \mathrm{BPD}, \mathrm{SOB}$ and gestational age for all babies and for each sex.

The male babies were observed to have a higher mean BW (3206 g) but lower BPD $(8.60 \mathrm{~cm})$ and lower SOB $(8.89 \mathrm{~cm})$ than the female babies with means of $2976 \mathrm{~g}, 8.73 \mathrm{~cm}$ and $9.99 \mathrm{~cm}$, respectively. The mean gestational age for all babies was 39.23 weeks (39.24 weeks for males and 39.21 weeks for females).

The mean BW, BPD, SOB of the babies as well as the mean maternal height (HT) and true conjugate of Groups Ia and Ib are shown in Table VI. A two-tailed T-test on the TC of Groups Ia and Ib was statistically significant indicating that patients who had c-section for CPD had a significantly smaller TC than those who had c-section for other indications $(P=0.0001)$. Also analysis of co-variance (Ancova) controlling for height in the two

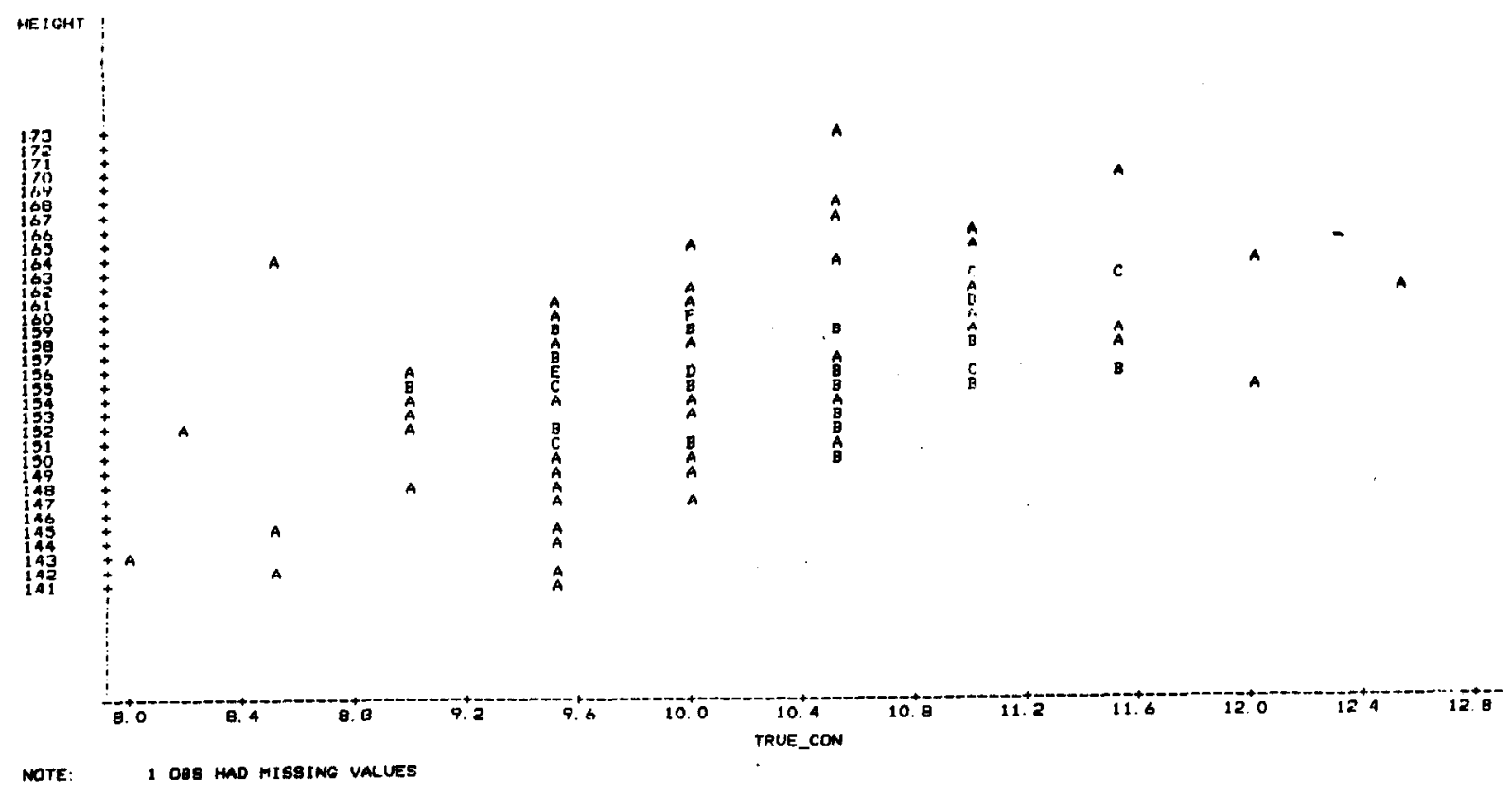

Fig. 5. Plot of height against true conjugate. 
Table III. Mode and outcome of previous deliveries. SVD, spontaneous vaginal delivery; VE, vacuum extraction; CS, cesarean section; LB, live birth; SB, stillbirth; NND, neonatal death (1st week).

\begin{tabular}{|c|c|c|c|c|c|c|c|}
\hline \multirow{2}{*}{$\begin{array}{l}\text { No. of } \\
\text { previous } \\
\text { deliveries }\end{array}$} & \multirow{2}{*}{$\begin{array}{l}\text { No. of } \\
\text { patients } \\
(N)\end{array}$} & \multicolumn{3}{|c|}{ Mode of previous deliveries } & \multicolumn{3}{|c|}{ Outcome of previous deliveries } \\
\hline & & $\operatorname{SVD}(\%)$ & VE (\%) & $\operatorname{CS}(\%)$ & LB (\%) & SB (\%) & NND (\%) \\
\hline $\mathbf{0}$ & 38 & & & & & & \\
\hline 1 & 76 & $64(84.2)$ & & $12(15.8)$ & $64(84.2)$ & $10(13.2)$ & $2(2.6)$ \\
\hline 2 & 49 & $41(83.7)$ & $1(2)$ & $7(14.3)$ & $44(89.8)$ & $3(6.1)$ & $2(4.1)$ \\
\hline 3 & 27 & $26(96.3)$ & & $1(3.7)$ & $24(88.9)$ & $3(11.1)$ & \\
\hline 4 & 16 & $14(87.5)$ & & $2(12.5)$ & $16(100.0)$ & & \\
\hline 5 & 10 & $9(90.0)$ & & $1(10.0)$ & $10(100.0)$ & & \\
\hline 6 & 7 & $6(85.7)$ & & $1(14.3)$ & $7(100.0)$ & & \\
\hline 7 & 3 & $3(100.0)$ & & & $3(100.0)$ & & \\
\hline 8 & 1 & $1(100.0)$ & & & $1(100.0)$ & & \\
\hline 9 & 1 & $1(100.0)$ & & & $1(100.0)$ & & \\
\hline
\end{tabular}

groups resulted in an $F$-value of 30.18 which was statistically significant, thus confirming the variation between Groups Ia and $\mathrm{Ib}(P=$ 0.0001).

The mean fetal BW in Group Ia (3101 g) was greater than in Group Ib (2980 g), but this difference was not statistically significant and therefore does not explain the variation between Groups Ia and Ib $(P=0.31)$. However, the difference between the TC and BPD was smaller in Group Ia (10.93 mm) than in Group Ib $(21.50 \mathrm{~mm})$ and this difference was statistically significant and thus does

Table IV. Indications for current and previous Cesarean section(s). CPD, cephalo pelvic disproportion; FD, fetal distress; APH, antepartum hemorrhage; CS, cesarean section.

\begin{tabular}{lllll}
\hline $\begin{array}{llll}\text { Current CS } \\
(N=79)\end{array}$ & \multicolumn{4}{l}{ Indications } \\
\cline { 2 - 5 } & CPD & FD & APH & Others \\
& $(\%)$ & $(\%)$ & $(\%)$ & $(\%)$ \\
& $34(43.0)$ & $23(29.1)$ & $5(6.3)$ & $17(21.5)$
\end{tabular}

No. of previous CS
\begin{tabular}{rcccc}
$1(N=66)$ & $24(36.36)$ & $22(33.33)$ & $5(7.58)$ & $14(21.21)$ \\
$2(N=10) 1 \mathrm{st}$ & $7(70)$ & $3(30)$ & & \\
2nd & $7(70)$ & $1(10)$ & & $2(20)$ \\
$3(N=4)$ 1st & $3(75)$ & & $1(25)$ & $1(25)$ \\
2nd & $3(75)$ & & & $1(25)$ \\
3rd & $3(75)$ & & & \\
\hline
\end{tabular}

explain the variation in the indication for csection in the two groups $(P=0.0015)$.

Analysis of variance (ANOVA) with the true conjugate as a dependent variable against BW, BPD and SOB gave an $F$ value of 10.56 and $P$ values of $>0.1$. Hence, BW, BPD and SOB do not explain a significant amount of the variation in the true conjugate of the patients who had c-section currently. Table VII shows the result of multiple correlation matrix with TC, BW, BPD and SOB as variables. The TC of patients who currently had csection is not significantly correlated with BW, BPD or SOB of the baby $(P>0.1)$. However, the fetal BW, BPD and SOB are significantly correlated with one another $(P$ $=0.0001$ ). Regression of the fetal $\mathrm{BW}$ as a dependent variable against maternal height gave an $F$ value of $3.116(P=0.0816)$. Thus, the maternal height does not explain a significant amount of the variation in fetal $\mathrm{BW}$ at the $0.05 \%$ level of significance. But if we are willing to increase the probability of a Type I error to $0.1 \%$, we may conclude that there is a trend for the maternal height to predict the fetal BW $(P=0.08)$.

\section{Discussion}

The dimension of the true conjugate in Ghanaian women has not been determined 
Table V. Mean BW, BPD, SOB and GA for (1) all babies, (2) males and females.

\begin{tabular}{lccc}
\hline & \multicolumn{3}{l}{ Mean \pm S.D. } \\
\cline { 2 - 4 } & All babies $(N=74)$ & Males $(N=40)$ & Females $(N=34)$ \\
\hline BW (g) & $3100.65 \pm 448.45$ & $3206.45 \pm 438.88$ & $2976.18 \pm 433.2$ \\
BPD (cm) & $8.66 \pm 0.66$ & $8.60 \pm 0.62$ & $8.73 \pm 0.70$ \\
SOB (cm) & $8.94 \pm 0.70$ & $8.89 \pm 0.71$ & $8.99 \pm 0.69$ \\
GA (weeks) & $39.23 \pm 1.21$ & $39.24 \pm 1.16$ & $39.21 \pm 1.29$ \\
\hline
\end{tabular}

previously. As masured intra-operatively with a caliper it was found to be $10.14 \mathrm{~cm} \pm 0.84$ S.D. This measurement included $0.5 \mathrm{~cm}$ thickness of the soft tissues covering the anterior and posterior aspects of the sacral promontory and pubic symphysis, respectively. Steward et al. [5] determined radiologically the antero-posterior diameter of the pelvic inlet of Shona and Zulu women in labor. Table VIII shows the comparison of the heights and true conjugates of Ghanaian, Shona and Zulu women. The heights of the Zulu were not stated in the publication. In our study, the mean HT and TC of patients who had c-section for CPD (Group Ia) as stated earlier (Table VI) was $152.68 \mathrm{~cm}$ and $9.54 \mathrm{~cm}$, respectively. Among the Shona, those who had major CPD in labor requiring c-section had a mean TC of $9.9 \mathrm{~cm}$ and a mean HT of $151.32 \mathrm{~cm}$ and the Zulu with major CPD had a mean TC of $9.6 \mathrm{~cm}$. Thus, all patients in the three different tribes who had CPD had a TC less than $10.00 \mathrm{~cm}$ and a HT less than $155 \mathrm{~cm}$, as compared to the controls whose HT was greater than $155 \mathrm{~cm}$ and

Table VI. Mean fetal BW, BPD, SOB and mean maternal height and true conjugate (Groups Ia and Ib).

\begin{tabular}{lcc}
\hline & \multicolumn{2}{l}{ Mean \pm S.D. } \\
\cline { 2 - 3 } & Group Ia $(N=34)$ & Group Ib $(N=45)$ \\
\hline BW $(\mathrm{g})$ & $3101.18 \pm 414.93$ & $2980.40 \pm 583.99$ \\
BPD $(\mathrm{cm})$ & $8.45 \pm 1.62$ & $8.46 \pm 0.82$ \\
SOB $(\mathrm{cm})$ & $8.64 \pm 1.68$ & $8.82 \pm 0.77$ \\
HT $(\mathrm{cm})$ & $152.68 \pm 5.46$ & $157.20 \pm 5.69$ \\
TC $(\mathrm{cm})$ & $9.54 \pm 0.63$ & $10.61 \pm 0.81$ \\
\hline
\end{tabular}

the TC greater than $10 \mathrm{~cm}$. Bernard (1952) found in a group of Scottish women whose TC were determined radiologically that women with a height of $5 \mathrm{ft}(152 \mathrm{~cm})$ had a TC of $10.8 \mathrm{~cm}$ and those with a height of $5 \mathrm{ft} 6$ ins $(167.64 \mathrm{~cm}) \mathrm{had}$ a TC of $12.7 \mathrm{~cm}$ and showed that the degree of mechanical difficulty in labor was inversely proportional to the patient's height [2]. Notwithstanding the fact that radiology was not used in our study, we observed a marked reduction in the true conjugate of the women who had c-section for CPD which had a statistically significant correlation with the height of the women (Fig.

Table VII. Multiple correlation matrix with TC, BW, BPD, and SOB as variables. (a) Pearson's correlation coefficient; (b) $P$-value.

\begin{tabular}{rllll}
\hline & \multicolumn{1}{l}{ TC } & BW & BPD & SOB \\
\hline TC (a) & 1.000 & 0.0385 & -0.1314 & 0.0328 \\
(b) & 0.000 & 0.7360 & 0.2516 & 0.7750 \\
& & & & \\
BW (a) & 0.0385 & 1.0000 & -0.5772 & 0.5797 \\
(b) & 0.7360 & 0.0000 & 0.0001 & 0.0001 \\
BPD (a) & -0.1314 & 0.5772 & 1.0000 & 0.6935 \\
(b) & 0.2516 & 0.0001 & 0.0000 & 0.0001 \\
& & & & \\
SOB (a) & 0.0329 & 0.5797 & 0.6935 & 1.0000 \\
(b) & 0.7750 & 0.0001 & 0.0001 & 0.0000 \\
\hline
\end{tabular}


Table VIII. Comparative height and true conjugate dimensions of Ghanaian, Shona and Zulu Women.

\begin{tabular}{|c|c|c|c|c|c|c|}
\hline & \multicolumn{2}{|c|}{ Ghanaian } & \multicolumn{2}{|l|}{ Shona } & \multicolumn{2}{|l|}{ Zulu } \\
\hline & CPD & $\begin{array}{l}\text { Con- } \\
\text { trols }\end{array}$ & CPD & $\begin{array}{l}\text { Con- } \\
\text { trols }\end{array}$ & CPD & $\begin{array}{l}\text { Con- } \\
\text { trols }\end{array}$ \\
\hline $\begin{array}{l}\text { Height } \\
\text { (cm) }\end{array}$ & 152.68 & 157.20 & 151.32 & 156.80 & & \\
\hline $\begin{array}{l}\text { True } \\
\text { conjugate } \\
\text { (cm) }\end{array}$ & $9.54^{\circ}$ & $10.61^{*}$ & $9.9^{h}$ & $11.5^{\mathrm{h}}$ & $9.6^{b}$ & $10.4^{b}$ \\
\hline
\end{tabular}

Caliper estimations; 'Radiological estimations.

5) $(P=0.0001)$. The mean maternal height of the Ghanaian was $156.06 \mathrm{~cm} \pm 5.93$ S.D. Among the Shona it was noted that the mean HT $(151.32 \mathrm{~cm})$ of women with major CPD was less than the mean HT (156.80) of those with no CPD [5]. We found that among the Ghanaians those in Group Ia had a mean HT of $152.68 \mathrm{~cm}$ as compared to a mean HT of $157.20 \mathrm{~cm}$ of those in Group Ib. This difference in height and true conjugate between the two groups in their obstetric performance was statistically significant $(P$ $=0.0007$ ). The mean TC in Group Ia was $9.54 \mathrm{~cm}$ whilst that in Group Ib was $10.61 \mathrm{~cm}$ (Table VI). Thus, patients who had c-section for CPD had a significantly smaller TC than those who had no CPD $(P=0.001)$. Furthermore, it was noted that the numerical difference between the TC and the BPD (i.e. TC minus BPD) was smaller in Group Ia $(10.93 \mathrm{~mm})$ than in Group Ib $(21.50 \mathrm{~mm})$ which clearly explains the failure of the fetus to pass through the pelvic inlet $(P=0.0015)$. Kratochwil and Zeibeki's (1972) showed by ultrasonic pelvimetry that the highest incidence of c-section for CPD was in the group of patients where the difference between the TC and the BPD was less than $10 \mathrm{~mm}$ [4]. Thus, the relation between the two parameters is of greater significance than their absolute values. The significant reduction among the Ghanaian women in the true conjugate (which in turn is a reflection of the small height of the women) explains, in the presence of an average-sized baby with a normal BPD, the rather high prevelance of CPD in the population. In a previous review of cases of obstructed labor at KATH (January 1974December 1977) out of a total of 41,585 deliveries, $642(1.5 \%)$ had obstructed labor. Five hundred seventy-seven $(89.88 \%)$ of these cases were due to CPD [1]. In the present study the highest c-section rate $(15.8 \%)$ was noticed among primiparae, likewise the highest stillbirth rate $(13.2 \%)$. Thereafter, the chances of having a SVD and a live birth increased with subsequent deliveries (Table III). Although the fetal BW, BPD and SOB show a significant correlation with one another, i.e. these variables increased with each other $(P=0.0001)$, they do not have any such correlation with the TC. The fetal BW, however, showed a weak correlation with maternal height. This would mean that taller mothers would tend to have larger babies. This correlation might perhaps find explanation in the larger weight of taller mothers. Eastman and Jackson (1968) found that, in general, fetal BW relates to pre-pregnancy maternal weight and paralleled the maternal weight gain in pregnancy [3]. The correlation between maternal height and the true conjugate with the rate of c-section for CPD even when the babies delivered by c-section in this study had only average BW and BPD is of importance in the initial categorization of patients, particularly primigravidae, into high and low risk groups at their first antenatal visit. Because of the result of this study, it is recommended that:

(1) All primigravidae with a height of $150 \mathrm{~cm}$ or less should be referred for delivery in a major hospital with c-section capabilities.

(2) Measurement of the true conjugate with the caliper is both simple and easy, poses no danger to the mother or baby, provides accurate and reliable estimates and should be done at all cesarean sections (particularly in primigravidae), laparotomies on 
nulliparae in their reproductive years, and in hospitals with no radiology or ultrasound facilities for antenatal pelvimetry. The true conjugate value so obtained should be documented in the operation notes and on the out-patient and identity cards for presentation at subsequent antenatal attendances and for future reference.

(3) Current data suggests that patients with a height of less than $155 \mathrm{~cm}$ and an estimated true conjugate of less than $10 \mathrm{~cm}$ who have had a previous c-section for non-CPD indication should not be submitted to a trial of labor in the presence of an average-sized baby. Prospective studies are needed to confirm this assumption.

\section{References}

1 Adadevoh SWK: Review of cases of obstructed labor at
Komfo Anokye Hospital, Kumasi, January 1974 to December 1977. Seminar on Emergencies. Ghana Medical Association/Friedrich Thieding Foundation of $W$. Germany. Kumasi, Sept. 11-13, 1980.

2 Bernard RM: The shape and size of the female pelvis. Transactions of Eninburgh Medical Society. Edinburgh Med J 59(1):1a, 1952.

3 Eastman NJ, Jackson E: Weight relationships to pregnancy. The bearing of maternal weight gain and prepregnancy weight on birthweight in full term pregnancies. Obstet Gynecol Surv 23:1003, 1968.

4 Kratochwil A, Zeibekis N: Ultrasonic pelvimetry. Acta Obstet Gynecol Scand 5:357, 1978.

5 Steward KS, Cowan DB, Philpott RH: Pelvic dimensions and the outcome of trial labour in Shona and Zulu primigravidas. S Afr Med J 55:847, 1979.

\section{Address for reprints:}

T.E. Elkins

Department of Obstetrics and Gynecology

University of Michigan Medical Center

1500 E. Medical Center Drive

D2234 MPB, Box 0718

Ann Arbor

MI 48109, USA 